\title{
Human Rights Education in the Chinese Context
}

\author{
Pinghua Sun *
}

Human rights education is an important measure for promoting respect for the fundamental rights and freedom of individuals. In the Chinese context, scholars have paid an increasing attention to human rights education. With special references to the UN Documents and relevant literature, the issues on human rights education in the Chinese context are worthy of being explored because HRE is both a requirement of the United Nations and China's national human rights action plan, a necessity in establishment of a harmonious society, and one that respects human rights in China. Human rights education has its own aims, functions and significance in China. The aim of this paper is to analyze the main factors affecting human rights education in China. In doing so, it examines multiple subjects, universal objects, rich contents and flexible methods. Based on aforementioned discussion, it points out existing problems affecting human rights education in China and puts forth strategies to deal with them.

Keywords: Human Rights Education, State's Obligations, Subjects, Objects, Methods, Problems and Strategies

* Professor at China University of Political Science and Law. M.A.(Warwick), Ph.D.(CUPL). ORCID: https://orcid.org/0000-0002-1930-638X. Much gratitude is extended to Professor Robin F. Wilson for her insightful comments and warm-hearted assistance in the proofreading process. The author may be contacted at: fadaphsun@aliyun.com/Address: China University of Political Science and Law, Xitucheng Road No.25, Haidian District, Beijing, P.R. China 100088. 


\section{INTRODUCTION}

The Universal Declaration of Human Rights ("UDHR") was adopted by the General Assembly in 1948. Its primary end is to promote respect for human rights and freedom. The UN proclaimed this document as a common standard of achievement for all peoples and all nations ${ }^{1}$ and expected every individual and every organ of society to "strive by teaching and education to promote respect for these rights and freedom." ${ }^{2}$ Through 70 years, the Declaration has committed a lot of efforts to proclaim the concept of human rights education ("HRE"). Its efforts have contributed to worldwide development and application.

HRE is a popular term in China. Scholars have published hundreds of journal articles discussing this topic in the past few years. The primary purpose of this research is to explore the issues on human rights education in the Chinese context. This paper will analyze main factors of HRE on the basis of the clarifications of its aims, functions and significance. Then, it will point out existing problems relevant to HRE in the Chinese context and put forth necessary strategies.

\section{Role of Human Rights Education}

Generally, human rights education plays an important role in promoting the values, beliefs and attitudes that encourage people to recognize their own rights and those of others. We can take advantage of HRE's ability to develop a mentality of common responsibility. This will realize human rights in each community. Specifically, the following are some of the purposes of HRE.

\section{A. Fulfillment of the UN Requirement}

The UDHR enjoins every member state, stakeholders and its organs to strive by teaching and education to promote the respect of rights and freedom. The UN human rights teaching seminar in Geneva, held on December 5-9, 1989, concluded: "It was very important to confirm that everyone was aware of his or her own rights, as human rights and fundamental freedoms should be guaranteed to everyone. Human rights teaching should thus be directed to every quarter."” This clarified in detail, who should receive HRE. 
On December 23, 1994, the UN General Assembly ("UNGA") adopted resolution A/RES/49/184, which proclaimed the United Nations Decade for Human Rights Education (1995-2004). ${ }^{4}$ On December 10, 2004, the UNGA proclaimed the World Program for Human Rights Education (2005-ongoing) to advance implementation of HRE programs in all sectors. ${ }^{5}$ This program seeks to promote a common understanding of basic principles and methodologies of HRE, to provide a concrete framework for action, and to strengthen the partnership and cooperation from the international level down to the grass roots. ${ }^{6}$

\title{
B. Fulfillment of a National Objective
}

On April 13, 2009, Chinese government issued the first National Human Rights Action Plan of China (2009-2010). ${ }^{7}$ In Section 4, the Action Plan provides in detail the regulation on HRE as follows:

\begin{abstract}
In the period 2009-2010, efforts will be made to disseminate knowledge of the law to the general public. The state was to actively rely on the present systems of compulsory education, secondary education, higher education and vocational education, training organizations in state agencies, as well as the media, including radio, television, newspapers, magazines and the Internet to popularize and spread knowledge of the law and human rights.
\end{abstract}

This section not only lists the subject (the state) and objects (students from schools at all levels) of HRE, but also clarifies its media and methods.

On June 11, 2012, the Chinese government issued the second National Human Rights Action Plan (2012-2015), which continued the planned strategy on popularizing HRE and even made more commitments. ${ }^{9}$ This shows how government is committed to HRE. It is committed to training civil servants to strengthen their awareness of human rights; supports human rights research institutions in an effort to develop teaching materials and participate in the training work; considers the inclusion of human rights education in primary and middle school curriculum; and encourages institutions of higher learning to offer courses on human rights and human rights theories. ${ }^{10}$ Moreover, this document pays attention not only to promoting the publicity of human rights knowledge in enterprises and public institutions, but also to enhancing human rights awareness among the whole populace. ${ }^{11}$ Compared with the first Action Plan, the second is a 
more concrete, practical and feasible, which provides guidelines for the practical human rights education in China. ${ }^{12}$

Even though eight National Bases for Human Rights Education and Training are now working, ${ }^{13}$ there still remains a lot of work to be done in human rights research and education to contribute to China's human rights protection.

At the second World Conference of Human Rights held on June 14-25, 1993 in Vienna, the Chinese government actively participated in all the discussions and negotiations, showing its interests, viewpoints and positions. Overall, the Chinese government exchanged opinions and attitudes frankly and openly with other countries, putting forth many suggestions and proposals, which facilitated different countries to reach a consensus. As a result, the Vienna Declaration and Programme of Action (hereinafter Vienna Declaration) was successfully adopted. ${ }^{14}$ Paragraphs 33-34 of the first section and Paragraphs 78-82 get involved in human rights education. ${ }^{15}$ The active participation clearly shows that Chinese government thinks highly of human rights education.

\section{Requirement of a Harmonious Society}

In a harmonious society, every individual's rights are guaranteed. It starts with raising awareness of a role well played by HRE. We cannot talk about human rights protection without education. It helps train people to resolve conflicts in a civil way. Wen and Liu believe:

The degree of a civilized society also depends on the degree of respect and value of the people. Social development needs universal human rights education, human rights knowledge is the prerequisite for individuals or groups to seek respect for human rights and freedom. Thus, people can consciously seek their deserved rights and respect for others' rights. Moreover, human rights education has become the foundation for prevention of social conflict by delivery of knowledge and enhancement of the skills and development of the concepts of human rights. ${ }^{16}$

ENCYCLOPEDIA OF Human Rights states in its "introduction by Chinese translators":

Enjoying sufficient human rights is a beautiful ideal that humans have long pursued. It is a complicated and systematic project to promote human rights. In the project, it is a crucial link to systematically carrying out theoretical researches, publicity and education 
in human rights, and popularizing fundamental knowledge of human rights, in order to enhance human rights awareness of every social member. ${ }^{17}$

Here pointed out are the beautiful ideal of the sufficient realization of human rights and the complicated implementation process with human rights studies and education as a crucial link. Enhancing human rights awareness of every social member is an effective measure to meet the needs of individuals.

\section{A Requirement for Living}

HRE is greatly valuable to individuals. Though the national legislation and the international conventions have developed systematic mechanisms of human rights protection at different levels, they cannot guarantee the full realization of human rights. For individuals, only when they are self-consciously aware of human rights, actively respecting and protecting human rights, they can ultimately realize human rights. In this case, "human-rights education has become a fundamental tool for promoting and protecting human rights in our country." realize human rights, individuals should be aware of human rights, which will become the prerequisite for respecting and promoting human rights. If individuals want to know what human rights are, they must receive human rights education. Shengkai Gu states: "If they were not made to know their own rights which should be enjoyed and how to realize these rights and how to get relief when their rights are violated, then these rights and freedom for them would be apparently the castle in the air and the object on the other planet."

The ultimate goal of HRE is to make individuals understand their own human rights and protect their own human rights, and "the development of the rightholders' human rights awareness through human rights education provides the right-holders with self-conscious awareness of human rights, active protection of human rights and ultimately facilitates the right-holders' initiative realization of human rights. ${ }^{20}$ In addition, understanding and awareness of human rights will benefit protecting individuals' human rights from being violated. Once their rights were violated, they could seek for remedy in time. With the development of their own concept of human rights, they will honor human rights, which will be helpful in protecting others' human rights unconsciously. From the aforementioned discussion, we can see that human rights education is also the need of individuals, 
which enables them to "understand their rights and consciously acknowledge the rights of others.",

\section{Aims, Functions and Significance of Human Rights EduCATION}

HRE has its own aims, functions and significance. It aims at delivering human rights knowledge, developing human rights skills, and strengthening respect for human rights and freedom. It will function in raising human rights awareness of individuals, establishing human rights culture, and promoting the realization of a harmonious society. Human rights education is significant in highlighting the value and dignity of persons, facilitating peace, justice and harmony of society, ensuring the long-term rule and security of the state and "promoting an active respect for human rights as formulated in the UDHR." ${ }^{22}$

\section{A. The Aims}

The aims of HRE can be discussed from the following three aspects: (1) delivery of human rights knowledge; (2) development of human rights skill; and (3) strengthening respect for human rights and freedom.

\section{Delivery of human rights knowledge}

Through HRE, the trainers will depart human rights knowledge among trainees. This knowledge will benefit the trainees a lot in raising their human rights awareness and highlighting the value and dignity of human beings. Because the knowledge received by HRE will lay a foundation for individuals' potential development, it will require having an adequate coverage of human rights content. The adequate coverage can meet the needs of individuals, including the concepts of human rights, the value and dignity of human beings, the fundamental rights and freedom, how to respect and safeguard human rights, how to get remedy when human rights are violated. ${ }^{23}$ In brief, HRE includes not only theoretical knowledge, but also abundant practical examples of application.

Furthermore, human rights knowledge is popularized through such educational approaches and channels as the media including radio, television, newspapers, 
magazines and the Internet, which will meet the needs of the new situation of the digital information era and serve as good measures to ensure the effectiveness of human rights education. ${ }^{24}$ Thus, HRE has become a fundamental tool to promote and protect human rights in our country.

\section{Development of human rights skills}

Through HRE, people develop human rights skills like mindfulness, respecting privacy, respectful social cues, and understanding controversial rights issues. "Human rights concepts also provide students with critical thinking skills in the field of social justice." ${ }^{25}$ Regarding human rights, they are usually associated with the following words: respect, safeguard, promote and realize. As usual, civil and political rights are called negative rights because they can be realized with the state's respect or without the state's interference, while economic, social and cultural rights are called positive rights because they cannot be realized without the state's efforts to take active measures. ${ }^{26}$ People thus often consider "respecting human rights" as negative rights, while they often do safeguarding, promoting and realizing human rights as positive ones. However, both negative and positive rights need human rights skills to be guaranteed.

Human rights skills can never be separated from human rights knowledge. Therefore, delivery of human rights knowledge is a very important preparation for the development of human rights skills. If a person has human rights skills, $\mathrm{s} / \mathrm{he}$ should know not only how to protect his/her own rights, but also how to prevent and get remedy in case of human rights violations.

\section{Strengthening respect for human rights and freedom}

China aims at "fully developing the humane personality and strengthening respect for human rights and fundamental freedom. ${ }^{27}$ HRE is also rich in content, which can be seen when referring to the training textbook for national cadres - "Human Rights Knowledge for Cadres' Reading." ${ }^{28}$ Regarding the people to be educated, human rights actions put an emphasis on HRE for public officials, reflecting the Chinese characteristics in implementing HRE.

In addition, educational methods and channels are used by public media such as broadcast, television, newspapers, journals, and Internet, which can be used to popularize human rights knowledge under this digital information era in the 
contemporary world. They are effective measures to guarantee HRE. Emphasizing HRE to governmental officers shows a feature of human rights education in China.

When discussing HRE in schools, Erping Li believes: "The aims of human rights education are to raise students' awareness of human rights and to develop students' concept of respect for and protection of human rights. In this sense, the education of human rights for students is believed as "quality-oriented education." ${ }^{29}$ Only through such a "quality-oriented education," will the students raise their own awareness and strengthen respect for human rights and freedom, which will lead to the establishment of human rights culture. Once human rights culture had been established, the level and degree of human rights protection would be gradually enhanced and advanced in the Chinese context.

\section{B. The Functions}

\section{Raising human rights awareness of individual values}

HRE can raise the awareness of individual human values. In traditional Chinese culture, people would rather take their duties and responsibilities than pursue their own rights. This kind of traditional culture has had an important influence on individuals' attitudes towards human rights. In contemporary China, traditional ideas should be changed according to the global trends of human rights protection. In modern time, all should be equally enjoying their human rights by law. In order to achieve this goal, HRE will play an important part because it "is an effective and important measure in improving human rights awareness $"$ "30 and individuals will raise their awareness of human rights protection by taking part in the process of HRE.

Though different programs should be designed for different groups of people in HRE, the essential sections cover the concepts and categories of human rights, international human rights system, international human rights conventions, domestic human rights law, human rights violations, human rights protection, and human rights culture, etc. All these aspects will enable individuals who receive HRE to have a better understanding of what human rights are and how to respect and protect human rights. With those ideas, individuals naturally can associate what they have learned with the reality in society. Then, they can be selfconsciously aware of human rights protection. All this process will benefit the whole society. 


\section{Establishing human rights culture}

HRE would establish a human rights culture. "The United Nations defines human rights education as training, dissemination and information efforts aimed at the building of a universal culture of human rights through the imparting of knowledge and skills and the moulding of attitudes." ${ }^{, 31} \mathrm{HRE}$ advocates for the respect and protection of human rights. In this society, people will take pride of their respecting human rights and condemn those who violated others' rights. If the whole society values and honors human rights, such a fashion will be confirmed. This will conversely influence individuals' behavior in their daily life. Throughout this process, respecting and safeguarding human rights will be a rule of society. However, it is not easy to settle down human rights as a culture. Therefore, HRE should be practiced as a life-long process.

Traditionally, every society has its own human rights value system. This will determine what, how and why they do or do not know and practice certain human rights. In order to establish a human rights culture, however, the majority of people should pay high attention to human rights. Today, China still has a long way to go for a human rights culture. Professor Ban discusses the basic concept of universal culture of human rights, which should be helpful to the universal respect for and realization of human rights. ${ }^{32}$ Then, he discusses the necessities, feasibility, basic approaches, and the requirements of establishing universal culture of human rights for HRE in China. ${ }^{33}$ In some sense, human rights education can play an important role.

\section{Promoting the Realization of a harmonious society}

HRE can help to solve the disputes in society in a civilized way and decrease the social conflicts, which will greatly benefit the establishment of a harmonious society. China emphasizes harmonious relationship between individuals, between individual and society, between individual and the state. ${ }^{34}$ In a harmonious society human rights are valued, honored, respected and protected. If so, the society must be civilized and harmonious. A person with better understanding of human rights can prevent human rights from being violated. HRE will help to realize this goal.

Regarding human rights education among college students, Professor Liyu Zhu points out: "To those students who may later become teachers, teaching staff, officials, law enforcement personnel and army men, the functions and influences 
of human rights education at universities are great." ${ }^{35}$ HRE is so great in promoting the respect for human rights and freedom in a harmonious society. Individuals will get along well with each other where human rights are respected. Here, people will treat others as brothers and sisters. In this case, all human beings will unite into a warm big family, which makes an ideal society.

\section{The Significance}

We can never keep aims, functions and significance of human rights education in isolation. "The development of a universal human rights culture will contribute to the promotion of universal respect for and the implementation of human rights, which has moral, legal and cultural significance."36

\section{Highlighting the value and dignity of persons}

HRE can both help people to recognize their rights and obligations, and highlight the value and dignity of persons. ${ }^{37}$ According to Chinese tradition, human beings are most valuable on earth and people are more precious than monarchs. ${ }^{38}$ Through HRE, people can have a better understanding of the value and dignity of persons. Yanlong Han states:

Human rights are the rights that every human being is entitled to enjoy. They are determined by human nature, which inevitably possesses two inseparable attributes the natural attribute and the social attribute. Every human being has the desire to pursue happiness equally without violating other people's rights. This desire is a powerful motive force for the development of human rights. ${ }^{39}$

Human beings can enjoy fundamental rights just because they are human. Human rights originate from human's values and dignity. Yong Xia maintains: "Everybody is a relatively self-supporting harmonious subject, and the existence of human beings has its dignity and value. Such dignity and value do not come from God, but from human beings themselves and from the universe and nature, so they are possessed by all human beings." ${ }^{40}$ With HRE, pursuing happiness is justified for everybody's human rights, which is of great significance for the establishment of human rights culture in China. 


\section{Facilitating social justice and harmony of a society}

HRE can help people intentionally or unintentionally promote and protect others' human rights rather than merely pursue their own rights. It will facilitate social justice and harmony of society. In China, social justice and harmony of a society are an ideal. Yong Xia also mentions: "In social life, everybody has or should have some interests, demands, qualifications, powers and functions and freedom, which mean some rights. These rights are essential to the survival and development of everybody and to the achievement of social harmony as well." ${ }^{, 41}$ Only when human rights are guaranteed, social justice can be ensured.

As HRE raises people's awareness of human rights, their ability to solve social conflict is developed. This avoids human rights violations effectively. According to Yong Xia, realistic harmony can be divided into three categories: "the harmony between human beings and nature; the harmony between man and man; and the harmony between physical and mental aspects of human beings. ${ }^{42}$ HRE can finally emphasize and cherish human values and dignity.

\section{Ensuring the long-term rule and security of the state}

"Respecting and safeguarding human rights" is a constitutional principle of China. ${ }^{43}$ By HRE, people would recognize not only their rights, but also their corresponding obligations. With a virtue of morality, people can learn to respect each other's values and dignity. In this case, HRE can lead to establishing a number of obligations and stable social relations, which are beneficial to the long-term rule and security of the state. Yong Xia says: "According to Chinese traditions, humanism is practiced with great harmony which is pursued not by means of emphasizing the rights of individuals, but their obligations and not by means of emphasizing the rule of law but the rule of virtue."

\section{Main Factors of Human Rights Education}

\section{A. Multiple Subjects of HRE}

HRE has its multiple subjects, including the state's responsibility of human rights education, teachers' involvement, the participation of individuals and the public, and others. 
The state is the most important factor in the whole process of human rights education. The Vienna Declaration and Programme of Action points out: "Human rights and fundamental freedoms are the birthright of all human beings; their protection and promotion is the first responsibility of Governments." ${ }^{.5}$ This Declaration clearly shows that the government should not only shoulder the responsibility of HRE, but also view it as its top priority. The Chinese government is obliged to develop the concept of human rights, to deliver human rights knowledge and skills, and to establish human rights culture for HRE. ${ }^{46}$ These duties and functions can be further divided into the following four aspects, namely, planning, organizing, coordinating and monitoring, among which planning is the prerequisite; organizing is the core; coordinating is the key; and monitoring is the guarantee. $^{47}$

Teachers' involvement is also an important part of HRE. Teachers from schools at different levels should actively participate in HRE as not only educators, but also trainees. ${ }^{48}$ Those teachers who have the expertise in HRE should take advantage of their profound knowledge of human rights protection for young students, who are from primary schools, middle schools, colleges or other kinds of special training schools. ${ }^{49}$ After school, most of these students may face many human rights issues. Once taking HRE, they would know how to respect and protect individuals' rights. For this purpose, HRE should encourage learners' active participations and roles in distributing human rights culture. In this sense, today's learners are potential teachers of future HRE.

Both individuals and the public are the important subjects in HRE, because every individual should value and respect the others' human rights. If every individual can autonomously consider the protection of human rights and is willing to do something for others' human rights, this will undoubtedly be daily HRE. Any persons with expertise and practical experiences of HRE can deliver lectures because they may have vivid examples to give the trainees. They are core players of HRE, as well.

\section{B. Universal Objects of HRE}

The objects of HRE are individuals, covering civil servants working in different national bodies and organs, students at different levels of school, and other group of persons who need to have some knowledge of human rights. HRE should have 
thus a systematic program for each of them.

Civil servants are directly managing national affairs. They should be aware of human rights protection in their daily work. Unfortunately, however, some of civil servants in China do not recognize the importance of human rights. Therefore, they are in great need of receiving human rights education. The National Human Rights Action Plan (2009) addressed:

\begin{abstract}
Human rights education and training will be carried out especially among government employees, focusing on people working in public security agencies, procuratorates, courts, prisons, urban management organs, and administrative law enforcement organs. The law enforcement departments will draw up their own plans for human rights education and training in line with their own work needs, highlighting publicity and education of regulations and laws on the protection of human rights, and give human rights education on a regular basis. ${ }^{50}$
\end{abstract}

Thus, crucial point of contention here is to give HRE to those who exercise public power in order to protect human rights in China more beneficially and increase its overall level of human rights protection. Public officials should be the main object of HRE, because they should not only enjoy their own rights, but also defend the rights of others. They are directly responsible for respecting and protecting human rights. HRE for public officials must focus on the aims and boundaries of public power in their discretion; it will improve their responsibility of human rights protection under the rule of law. If the public officials are fully aware of domestic and international human rights protection system, their daily practice will respect and safeguard human rights overall. ${ }^{51}$

HRE in primary and middle schools is the basic program, while the college level is a higher stage. For the primary and middle school students, HRE can be included in legal and moral education subject. Meanwhile, college students can take human rights courses, because such courses will provide them with quite significant and practical measures for their preparatory work.

In addition, the populace is the largest group of people who needs HRE. The general goal of human rights protection is to guarantee every individual's human rights and to promote "an active respect for human rights." ${ }^{, 52}$ When their rights are violated, these individuals should invoke the human rights protection nationally and internationally. However, because the populace has little knowledge of human 
rights protection, they may have no idea as such and even do not know what their rights are on many occasions. Therefore, the first task is to raise their awareness of human rights protection by HRE.

\title{
C. Rich Contents and Flexible Methods of HRE
}

The National Human Rights Action Plan (2009) set forth detailed regulations on HRE. Section IV provides:

\begin{abstract}
In the period 2009-2010, along with the dissemination of knowledge of the law among the general public, the state will actively rely on the present systems of compulsory education, secondary education, higher education and vocational education, training organizations in state agencies, as well as the media, including radio, television, newspapers, magazines and the Internet, to carry out human rights education in various forms in a planned way, popularizing and spreading knowledge of the law and human rights. $^{53}$
\end{abstract}

If the college students are non-law major, they should have optional public training in human rights, in which basic knowledge of human rights should be covered, such as the definition of human rights, for example, religious freedom and LGBT (Lesbian, Gay, Bisexual and Transgender) rights, ${ }^{54}$ the nature of human rights, the categorizations of human rights, historical development of human rights, human rights protection system, etc. Erping Li believes that the content of HRE in Chinese universities should be developed and expanded at the following seven levels: "the core values of human rights, the characteristics and particularity of human rights, basic concepts of human rights, history of human rights, the content of human rights, human rights practice, and practical issues of human rights. ${ }^{, 55}$ For the law students, their courses should cover specific knowledge of international human rights conventions and their implementing mechanism.

HRE methods are also important to enrich the content of classroom practice. Systematic approaches consist of lectures, discussion and group learning, peer teaching, oral presentation, and project work. Lectures are main approaches for transmitting new information. They may also contain different teaching styles by inviting the natures of seminars, negotiations and solutions of problems. Discussion and group learning are to develop students' ability to learn collaboratively and solve problems cooperatively. Peer teaching is the opportunity 
for trainees to experience what they have learned and this method can help each other to gain some insights through collaborative preparation and presentation phases associated with their prior experience. Oral presentation is a method to offer the opportunities to turn the knowledge into practice, which will serve the preparatory stage for their later real social practice in the aspect of human rights protection. Project work is to deliver a kind of skill for their lifelong education. To be more exact, it is a kind of small-scale research built up in classroom context, but will play an important role in HRE.

\section{Problems and Strategies in Human Rights Education}

HRE has become the basic means of improving and protecting human rights in China. ${ }^{56}$ However, there are still many problems and steps to transform abstract regulation to specific implementation measures for human rights education listed in the National Human Rights Action Plan. Apart from the overall planning, specific numeric goals and detailed implementation procedures and plans are necessary for various forms of HRE. Only through careful work can these goals for HRE be completely achieved. In this case, strategies should be employed for a better solution.

\section{A. Problems in HRE}

Traditionally, 'human rights' was a sensitive term due to political factors. However, the state cannot keep away from its major responsibilities and duties including human rights protection and education. China is paying much attention to the significance of HRE, but, owing to its weak foundation, there are still many problems to deal with effectively. Professor Youwu Chen maintains: "Human rights education as a discipline is relatively at a low rank, the ways of the education are limited, few universities have offered courses on human rights, few students have received human rights education, and disciplinary backgrounds of the teachers are diversified, both subject of duty and adequate faith are lacking in human rights education." ${ }^{57}$

Professor Wenzhan Ban tells: "Because Chinese legal education and moral 
education have different goals and content from that of human right education and it is neither systematic nor popular of the given individual or professional training, there exists a great limit to promote the realization of the goals of human rights education." ${ }^{58} \mathrm{He}$ further points out that "the existing human rights education belongs to few units and few individuals' behavior, ... which has the nature of great random and uncertainty."

\section{Lack of ready-made course materials}

No one can teach human right without course material like textbooks, treatises and written research. Teaching materials or textbooks are one of four core factors in education which are still in great need. For different groups of people who have different needs, it is very difficult to get the suitable textbook for HRE. On the one hand, the HRE textbooks are rare in China. On the other hand, as HRE has just started, basic constructions including textbook design are still very weak. The existing course has not formed a systematic series of textbooks on human rights. This will have a negative influence on the successful achievement of HRE. As lack of materials and textbook will lead to diversify the classroom teaching, teachers would usually choose the materials randomly, which cannot ensure the standards of human rights course. Furthermore, it is difficult to find the textbooks for civil servants and the populace which contain universal principles of human rights. In fact, however, lack of well-compiled textbooks can be solved by adopting the strategies of organizing first-class experts to compile textbooks. ${ }^{60}$

For historical and cultural reasons, human rights courses in the formal curriculum are included in only a few universities. According to Professor Shiyan Sun, "[T]here are more than 1,600 universities, more than 300 law schools or departments in China, but only 15 ones run human rights course independently, less than 5 percent of the law schools or departments." ${ }^{, 61}$ By October 2008, there were about 30 law schools or departments running human rights courses. ${ }^{62}$ A more recent research shows that, as of July 2012, there were about 60 laws schools or departments running human rights courses. The assessment report addressed in 2016:

In accordance with the requirements in the Action Plan, institutions of higher learning strengthened the development of human rights related majors, offered related courses for four-year college students majoring in law, compiled human rights teaching materials 
and accelerated the education for special talents on human rights. They enriched courses on human rights education by independently offering the general course, "Introduction to Human Rights" and some selective courses including "Human Rights Law," "International Human Rights Law," and "Special Features on Human Rights Law." Institutions of higher learning enrolled masters and Ph.D. candidates in disciplines including human rights law, politics and philosophy of human rights, and set up postdoctoral research centers in human rights. ${ }^{63}$

Despite this rapid development for the past few years, there remain a lot of difficulties before China.

\section{Lack of qualified teachers}

In addition to course materials, lack of qualified teachers is a serious problem in China. Because HRE just started a few years ago, not many qualified human rights specialists have been cultivated yet. In China, there are no qualification standards for human rights educators. Without concrete standards, different groups of people have been involved in HRE from the legislature, judiciary, and law practitioners. ${ }^{64}$

Even though those teachers or professors have profound knowledge of their special areas, they may lack systematic human rights knowledge. However, as a special course, HRE requires educators with knowledge, to develop human rights skills, and ultimately to establish a human right culture. To meet all these ends, we need a large group of teachers or educators.

\section{Lack of the support for systematic research}

HRE should be supported by theoretical research. HRE and theoretical research cannot be kept in isolation. In practice, systematic research will support HRE. Without the systematic theory, it is difficult to practice HRE.

A noticeable example shows that the theoretical research of human rights has made a great contribution to marriage, family and religious rights in Europe and America. ${ }^{65}$ HRE without theoretical ground is a blind education, while theories without any practical implication are groundless. Only when integrating HRE with theoretical research, HRE may produce more effective and efficient results. The following are the strategies for HRE. 


\section{B. Strategies in HRE}

Professor Youwu Chen suggests such solutions to the problems mentioned above as: "enhancing the awareness of HRE in universities, the state playing its role in this education, reinforcing the construction of human rights education as a discipline and consolidating its foundations of faith." ${ }^{66}$ The following are some of my proposals.

\section{Organizing first-class experts to compile textbooks}

Though it has not been long for HRE, China nowadays has got dozens of universities to run human rights courses. However, compiling HRE textbooks is a premise in China. Different universities should join efforts and expertise to make contributions to HRE by compiling textbooks or developing teaching materials. As HRE is a great career, attracting the government's attention, a group of human rights scholars are appearing.

Hundreds of research articles can be searched under the title of "human rights education" in China. It means that many scholars have been keeping their eyes on HRE in China. For better HRE, these experts should be organized to compile textbooks for this field. In addition, national bases for HRE and training established in the past years should take this opportunity to gather the experts together to conduct research on HRE and related issues in China. An agenda to publish human rights textbooks embracing the value of China's experience on HRE should be started. This will serve as a foundation for materials design and textbook development. There is still a long way to go, however. ${ }^{67}$

\section{Speeding up the cultivation of qualified specialists in human rights}

Lack of qualified teachers is another serious problem at a policy-making level. It is one of the reasons why human right courses are still marginalized and the curriculum is undeveloped. Meng Sun has pointed out that this problem is responsible for the lack of HRE at most of universities in China. ${ }^{68}$ She further believes that "human rights law is a comprehensive subject covering all the branches of law." ${ }^{69}$ Therefore, it is hard to find teachers who have both profound and extensive understanding, and ability to integrate it from different branches of law in order to form a systematic knowledge structure and to deliver the significance and values of human rights to the students. 
Because of the high demand for qualified specialists in human rights law, China should fast cultivate and provide sufficient number of qualified teachers for HRE. Today, some universities such as Nankai University, China University of Political Science and Law ("CUPL"), Shandong University, etc. are running MA programs in human rights law successfully. In particular, CUPL has a Ph.D. program in human rights law. ${ }^{70}$ This is just a beginning. With the development of HRE, more qualified specialists are expected to appear in human rights area.

\section{Conducting systematic research to establish the system of human rights theories} To strengthen HRE, China should strengthen research work on human rights theory and practice. Popularization of HRE is a good starting point. Strengthening HRE and researching human rights theory and practice are mutually supplementary. ${ }^{71}$ If unifying HRE with theoretical research and practice, human rights protection will not be undervalued in society.

Human rights research can effectively support theories for HRE. In this regard, basic concepts of human rights and specific issues should be clarified in order to construct a series of systematic theories. At a macro level, human rights research should focus on the international human rights regime, regional human rights system and domestic human rights protection. ${ }^{72}$ Based on the core concept, human rights should be distinguished from politics, economics, society, culture, law and history.

From an inter-disciplinary viewpoint, human rights research should distinguish human rights from the dominance of law, philosophy, ethnics, political science, sociology, psychology, anthropology and international relations. Therefore, human rights research itself is a very complicated system. Systematic research should cover different areas of human rights, which will be beneficial to establishing the scientific system of human rights theories.

In human rights research, on the one hand, core concepts are clarified; whole picture of human rights theories is described; theoretical system is constructed; and different theories relevant to human rights are enriched and perfected. All these systems will support HRE. On the one hand, the content of human rights research can be used as teaching materials, which will play a part in HRE. On the other hand, through human rights research, many questions on human rights protection can be better understood, which is much beneficial to promoting human rights. ${ }^{73}$ 


\section{Conclusion}

Recently, HRE is a popular topic in China because it is both a requirement of the UN and international law. The Chinese government has in respect to this obligation issued three National Human Rights Action Plans, which have served as guidelines for Chinese human rights protection and education. HRE has its own features including multiple subjects, universal objects, rich content and flexible methods.

The aims of HRE are to impart human rights knowledge, to develop human rights skills, and to strengthen respect for human rights and freedom. Therefore, HRE plays an important role in raising human rights awareness of individuals, establishing human rights culture, and promoting the realization of a harmonious society. HRE is of significance for highlighting the value and dignity of persons, facilitating peace, justice and harmony of society, and ensuring the long-term rule and security of the state.

However, there are still many existing problems in HRE of China. These include a lack of well-compiled textbooks, qualified teachers, and systematic research support. In this case, some effective strategies should be adopted to cope with these problems. China must organize first-class experts to compile textbooks; speed up the cultivation of qualified specialists in human rights; conduct systematic research to establish the human rights theories; and take active part in the international communication in human rights area. Though HRE is just at the initial stage in China and efforts should be taken to develop a good HRE system, HRE is a promising enterprise for further promoting the full realization of human rights in China. Hopefully, a good HRE system will be set up in China in the near future. 


\section{REFERENCES}

1. Pinghua Sun, Historic Achievement of a Common Standard: Pengchun Chang and the Universal Declaration of Human Rights 350 (2018).

2. UDHR, pmbl. For details, see Pinghua Sun, The Study of the Universal Declaration of Human Rights [<世界人权宣言〉研究] App’x 3 (Peking University Press, 2012).

3. Report of the United Nations Seminar on th e Teaching of Human Rights, U.N. Doc. E/CN.4/ 1989/68, ๆ 121, available at https://digitallibrary.un.org/record/56710/files/E_CN.4_1989_68EN.pdf (last visited on Jan. 31, 2019).

4. G.A. Res. 49/184, U.N. Doc. A/49/184 (Dec. 23, 1994), available at http://www.un.org/ documents/ga/res/49/a49r184.htm (last visited on Jan. 25, 2019).

5. G.A. Res 59/113/A, U.N. Doc. A/59/113 (Dec. 10, 2004), available at http://www.un.org/en/ ga/search/view_doc.asp?symbol=A/RES/59/113 (last visited on Jan. 26, 2019).

6. World Program for Human Rights Education (2005-ongoing), available at https://www. ohchr.org/en/issues/education/training/pages/programme.aspx (last visited on Jan. 26, 2019).

7. Information office of the State Council, of the People's Republic of China, National Human Rights Action Plan (2009-2010), Apr. 13, 2009, available at http://www.bjreview.com. cn/special/Human_Rights_Action_Plan_2009-2010/2009-12/02/content_232193.htm (last visited on Jan. 26, 2019).

8. See National Human Rights Action Plan of China (2009-2010): IV. Education in Human Rights, BeIJng Rev, Dec. 2, 2009, available at http:/www.bjreview.com.cn/special/Human Rights_Action_Plan_2009-2010/2009-12/02/content_232193_25.htm (last visited on Jan. 26, 2019).

9. Information Office of the State Council of the People's Republic of China, National Human Rights Action Plan of China (2012-2015), available at http://www.china.org.cn/government/ whitepaper/node_7156850.htm (last visited on Jan. 25, 2019).

10. See Human Rights Education, available at http://www.china.org.cn/government/ whitepaper/2012-06/11/content_25619807.htm (last visited on Jan. 26, 2019).

11. Id.

12. Pinghua Sun, Human Rights Protection System in China 273-303 (2014).

13. In 2011, three National Bases for Human Rights Education and Training were set up at Nankai University, China University of Political Science and Law, and Guangzhou University. In 2014, five more National Bases for Human Rights Education and Training were set up at Renmin University of China, Fudan University, Wuhan University, Shandong University, and Southwest University of Political Science and Law. According to the new National Human Rights Action Plan (2016-2020), the Chinese government is planning to set up another five National Bases for Human Rights Education and Training. See State Council Information Office of PRC, National Human Rights Action Plan (2016-2020), available at http://www.scio.gov.cn/wz/Document/1492804/1492804.htm (last visited on Jan. 31, 2019). 
14. Vienna Declaration, available at https://www.ohchr.org/en/professionalinterest/pages/ vienna.aspx (last visited on Jan. 25, 2019).

15. Id.

16. Weiyong Wen \& Yi Liu, Value analysis of human rights education [人权教育的价值分析], 11 LEGAL System \& SOC’y [法制与社会] 318 (2009).

17. E. Lawson, Encyclopedia of Human Right 7 (1997).

18. Sun, supra note 12, at 101.

19. Shengkai $\mathrm{Gu}$, Human rights education viewed from the international human rights law [国际 人权法视野下的人权教育], 6 Hum. RTs. [人权] 43 (2006).

20. Fangfang Liu, The study of the state's international legal obligations in human rights education [国家在人权教育方面的国际法律义务研究] (2010) (unpublished MA dissertation, CUPL).

21. Sun, supra note 1, at 210.

22. C. Lohrenscheit, International approaches in human rights education, 48 INT'L Rev. EDUCATION 173-85 (2002).

23. F. von Harbou, A remedy called empathy: The neglected element of human rights theory, in 99(2) Archives for Philosophy of Law and Social Philosophy 133-51 (2013).

24. Pinghua Sun, Fundamental principles for achieving international human-rights standards in China, in Fundamental Rights in Europe and China 21-40 (L. Rossi \& G. Federico eds., 2013).

25. J. Martin, Human right: Education for what?, 9 Hum. RTs. Q. 414-22 (1987).

26. Sun, supra note 2, at 3.

27. UDHR art. 26 (Item 2).

28. National Steering Committee on Reading and Editing of Training Materials for Cadres (ed.), Knowledge on Human Rights for Cadres’ Reading [人权知识干部读本] (People's Press, 2006).

29. Erping Li, Human rights education in Chinese Universities [中国大学的人权教育], 1 Hum. RTS. [人权] 46-7 (2007).

30. Sun, supra note 1 , at 332 .

31. S. Cardenas, Constructing rights? Human Rights Education and the State, 26 InT'L Political ScI. Rev. 363-79 (2005). [Emphasis added]

32. Wenzhan Ban, On the development of universal human rights culture and the promotion of human rights education in China [普遍人权文化的建立与中国人权教育的开展], 8:1 J. GuANGZHou U. (Social Science Edition) [广州大学学报] 3-9 (2009).

33. Id.

34. According to Confucius, “In carrying out the rites it is harmony that is prized [礼之用, 和为 贵].” See Sun, supra note 12, at 6-7.

35. Liyu Zhu, On Several Issues to Promote Human Rights Education in Chinese High Educational Institutes [关于我国高校进一步开展人权教育的几个问题], 3 Hum. RTs. [人权] 
54-8 (2012).

36. Ban, supra note 32 .

37. Pinghua Sun \& Hanling Wang, Attitudes should be taken by China towards the Declaration on Human Dignity [试论我国对 <人的尊严宣言> 应采取的态度], 2 MotHERLAND [祖国] 52-5 (2019).

38. Mencius said: "The people are the most important element in a nation; the spirits of land and grain are the next; the sovereign is the lightest.” See The Work of Mencius, pt. 2: ch. 14 (Tsin Sin) 359 (J. Legge trans., 2014).

39. Yanlong Han, Legal protection of human rights in China, in Human Rights: Chinese AND Dutch Perspectives 91-101 (P. Baehr, F. van Hoof, Nanlai Liu and Zhenghua Tao eds., 1996).

40. Yong Xia, Human rights and Chinese tradition. in Human Rights: Chinese And Dutch Perspectives 77-90 (P. Baehr, F. van Hoof, Nanlai Liu and Zhenghua Tao eds., 1996).

41. Id.

42. Xia, supra note 40.

43. P.R.C. Const. (2014 Amendment), art. 33, $₫ 3$.

44. Xia, supra note 40.

45. Vienna Declaration, art. 1, 93.

46. Fengyun Wang, Internal structure of our government's duties and functions of human rights education [我国政府人权教育职能的内在架构], 33 ECON. VISION [经济视角] 125-6 (2011).

47. Id.

48. S. Urman, Human rights education: A legal and moral imperative, 11 CAN. J. EduCATION. 383-7 (1986).

49. Sun, supra note 12 , at 75.

50. National Human Rights Action Plan (2009-2010), supra note 7.

51. Sun, supra note 12, at 110.

52. Lohrenscheit, supra note 22, at 173-85.

53. National Human Rights Action Plan (2009-2010), supra note 7.

54. W. Eskridge, Jr. \& R. Wilson (eds.), Religious Freedom, LGBT Rights, and the Prospects FOR COMMON GROUND (2018).

55. Li, supra note 29.

56. Sun, supra note 24.

57. Youwu Chen, Problems in Human Rights Education in China's Universities and the Solution [高校人权教育中存在的问题及其完善], 9:1 J. GuANGZHou U. (Social Science Edition) [广州大学学报] 25-8 (2010).

58. Ban, supra note 32.

59. Id.

60. National Human Rights Action Plan (2009-2010) points out: "The government will organize experts to compile special textbooks for human rights training." See supra note 8. 
61. Shiyan Sun, Present situations and considerations of human rights law teaching in college legal education [大学法律教育中人权法教学的现状与思考], 6 Hum. RTs. [人权] 43-6. (2005).

62. Chen, supra note 57.

63. Assessment Report on the Implementation of the National Human Rights Action Plan of China (2012-2015), June 14, 2016, available at http://www.chinahumanrights.org/ html/2016/NHRAPC_0614/5056_2.html (last visited on Jan. 25, 2019).

64. U.N. Doc. E/CN.4/1989/68, \121.

65. R. Wilson, The Contested Place of Religion in Family Law (2018).

66. Chen, supra note 57.

67. Sun, supra note 12, at 113-5.

68. Meng Sun, Issues of human rights education viewed from human rights laws teaching at universities [从高校的人权法教学看人权教育问题], 4 Mod. EDUCATION SCI. [现代教育科学] 1479 (2007).

69. Id.

70. CUPL started to recruit Ph.D. candidates in 2007, and the author was awarded Doctorate degree in human rights law by CUPL on January 8, 2010, becoming the first person with human rights law degree in China. For details, see Institute for Human Rights, A National Base for Human Rights Education and Training, available at http://rqyjy.cupl.edu.cn/index. htm (last visited on Jan. 25, 2019).

71. Sun, supra note 12, at 113.

72. Sun, supra note 2, a 7.

73. Martin, supra note 25. 